\title{
The Prevalence of Stereotypes Against the LGBTQ Community and the Effect of Education on Those Stereotypes
}

\author{
Heather Wickersham ${ }^{1}$ and Deborah Vajner ${ }^{1}$ \\ ${ }^{1}$ Terry Sanford High School, Fayetteville, NC, USA
}

\section{ABSTRACT}

Stereotyping against the LGBTQ community is a major problem in modern society. Previous research has shown that stereotypes can be reduced through targeted education about the stereotyped group. This study aims to further research the effect of education on stereotypes as well as the prevalence of stereotypes against the LGBTQ community in a public high school in North Carolina. Building on existing work from Canada, this study questions the use of education in changing stereotypes and what is the baseline prevalence of those stereotypes.

Based on the previous peer-reviewed, published literature, this study will survey both students and teachers to establish a baseline of stereotyping occurring at this location. The researcher will teach a class about stereotypes and the LGBTQ community and measure the level of stereotypes before and after the presentation. The analysis showed that this high school had low levels of discrimination, which is a major sign of low levels of stereotyping. It also showed that education had a low-grade negative impact against stereotyping, effectively increasing stereotyping.

\section{Introduction}

Stereotypes are a fact of life. They inform the human mind about groups of people, acting as a mental shortcut to form opinions (McCormick). There are pros and cons to using shortcuts. In the context of social life, stereotypes provide simplified, general ideas about people. How these ideas are used as information in decision-making can determine if the stereotype is positive or negative (McCormick). Inaccurate stereotypes are common. When false, stereotypes negatively affect the people being stereotyped. Stereotypes are preconceived ideas or beliefs that are typically negative (Teaching Tolerance, 2019). The act of stereotyping people involves over-generalizing their characteristics and placing them into categories (Teaching Tolerance, 2019). These characteristics include race or ethnicity, gender, sexual orientation, age, ability, physical appearance, class or socioeconomic status, occupation, etc. (Teaching Tolerance, 2019).

Stereotypes can create social stigma, which marks an individual or group as undesirable (Williams \& Mann, 2017). This can lead to devaluation. Devaluation occurs when there is a constructed stigma, and the stigmatized persons result in poorer economic and interpersonal outcomes because of the labeling, stereotyping, separation, status loss, and discrimination (Williams \& Mann, 2017). Structural discrimination through policy negatively affects the LGBTQ community regularly (Williams \& Mann, 2017). Stigma has been proven to be a fundamental cause of health disparity (Williams \& Mann, 2017). For the LGBTQ community or the sexual minority, this stigma causes extensive distress thus harming the health of the LGBTQ community, until there is a change in the discriminating policy or unless the stigmatized persons are using adequate coping mechanisms (Williams \& Mann, 2017). For example, psychiatric morbidity increased in sexual minorities the year following a ban on same-sex marriage, resulting in a $250 \%$ increase in general anxiety disorder, a 37\% increase in mood disorders, and a $42 \%$ increase in alcohol disorders (Williams \& Mann, 2017). 
Many well-known stereotypes in the larger part of society are about minority groups. The LGBTQ community is comprised of lesbian, gay, bisexual, transgender, and queer or questioning individuals. The American public has been presented with stereotypes about the LGBTQ community that typically illustrate a negative connotation, leading to discrimination and exploitation.

Statistics bring the nuances of stereotyping in our society into the light where they can be seen and re-evaluated. A previous study, "Measuring the effect of sexual orientation on income: Evidence of discrimination?" by Berg and Lien, concluded that non-heterosexual men earned 22\% less than heterosexual men (Berg \& Lien, 2002). Regarding the perception of being hireable, gay male and lesbian job applicants were perceived to be less competent than heterosexual men, but more competent than heterosexual women (Niedlich \& Steffens, 2015). Lesbian and gay job applicants were rated higher in both task competence and social skills when compared to heterosexual applicants who were equally qualified (Neidlich \& Steffens, 2015). This phenomenon is an example of positive discrimination that favored the sexual minority with being awarded jobs (Neidlich \& Steffens, 2015). Heterosexual women are negatively discriminated against in the job market when positive discrimination favors homosexual women.

My research will explore past research on the topic of stereotypes against the LGBTQ community in general society, as well as in schools. It will then address the gap, the prevalence of stereotyping in a North Carolina high school. This will be studied through four surveys, three surveys of the students, and one survey of the teachers to compare the effect of education on stereotypes as well as seeing how in tune the teachers are to the stereotypes held by the student body. Then the paper will discuss the findings and will also compare the high school studied to literature sources.

\section{Literature Review}

The stereotyping of LGBTQ individuals has been previously researched and is well-documented. Homosexuality is a controversial topic in many places globally. In 1973, the American Psychiatric Association (APA) removed homosexuality being defined as a mental disorder from the book Diagnostic and Statistical Manual of Mental Disorders because after comparing competing theories regarding homosexuality: pathology, immaturity, and normal variation, and concluding that homosexuality was a normal variation (Drescher, 2015; Schlanger, 2017). Before 1973, homosexuality was considered a mental illness (Schlanger, 2017). Even though Americans have generally grown more accepting of the LGBTQ community, change has been slow while this community continues to suffer from the disadvantages and harm of negative stereotyping. Decades of stigmatizing homosexuality as a mental illness combined with the stigma of being gay as pathological have largely remained in American culture (Schlanger, 2017). Americans typically cite religious beliefs when explaining their refusal to accept members of the LGBTQ community as normative (Schlanger, 2017).

Sexual minority refers to lesbian, gay, bisexual, or any other sexual orientation different than heterosexual (Chaudoir et al, 2017). The sexual minority experiences stigma-related stress, although it is less severe in recent decades in the United States than it used to be (Chaudoir et al, 2017). The improvement in the health and coping mechanisms of the sexual minority is attributed to the gay rights movement in the 1970s and encouragement to the sexual minority to "come out" (Chaudoir et al, 2017). Lower stress for the sexual minority may be attributed to education. Although progress has been made, many members of the sexual minority continue to occupy positions of inferiority and devaluation as a result of numerous forms of societal stigma (Chaudoir et al, 2017). Also due to societal stigma, there is a significant disparity between the health of the heterosexual and sexual minority communities (Garbers et al, 2018). Sexual minorities have higher rates of sexually transmitted infections, HIV, and pregnancy, which may stem from stigma, discrimination, and victimization experienced at home, community, and school (Garbers et al, 2018). Specific support systems have been proven to reduce these disparities, including specific school climate elements (Garbers et al, 2017). The presence of a Gay-Straight Alliance support group, inclusive curricula, anti-bullying policies, trained staff, and nondiscriminatory policies, have been shown to reduce the disparity between the health of heterosexuals and sexual minority (Garbers et al, 2017). 
The formation and shaping of stereotypes are generally shown to be influenced by contact with homosexual individuals and through role-modeling (Greenburg \& Gaia, 2019; Phillips \& Clark, 2012). As Americans become more accepting of the queer community, more individuals have safely come out. This has slowly increased awareness because Americans are exposed to the queer community through television and interpersonal communication. The increase in exposure is most likely partially responsible for further increases in acceptance, because of the intergroup contact theory which states that conflict between groups can be reduced through contact; therefore, stereotypes can be influenced by direct contact with queer individuals (Greenburg \& Gaia, 2019).

Over time, adolescents' attitudes tend to become more favorable (Smith et al, 2015). Time combined with education renders an increase in tolerance toward disadvantaged groups, thus accelerating the rate at which tolerance increases and manifests itself in social settings (Smith et al, 2015). The practice of perspective-taking showed a possible inroad to reducing prejudice among adolescents (Smith et al, 2015). The ability to take the perspective of another individual is a skill that the brain naturally develops through maturation, which explains why the older an adolescent becomes, the greater the amount of empathy he possesses (Smith et al, 2015). However, it may be possible to increase tolerance in adolescents at younger ages than is statistically typical with targeted education. Education for adolescents could include targeting perspective-taking (Smith et al, 2015).

The formation of general stereotypes and how they infiltrate society every day often hides behind ambiguity, body language, and sarcasm. This trend is dubbed the "hidden curriculum" (Phillips \& Clarke, 2012). The silent thought process inside one's head offers no explanation or rationality as to why a teacher may not opt to select an LGBTQ student for a leadership position, a role in a play, or a place on the sports teams. A qualitative study funded by the Department of Family Medicine at Queen's University in Ontario, Canada, attempted to uncover the establishment and practice of prejudice (Phillips \& Clarke, 2012). The study found words, attitudes, and behaviors that students had witnessed in the classrooms to be discriminatory toward a group of people (Phillips \& Clarke, 2012).

In schools, the primary role-model for students is their teacher (Preston, 2016). Some high schools employ sexuality teachers whose job is to teach the students about sex and sexuality. A qualitative study published in 2016, titled “'They're Just Not Mature Right Now': Teachers' Complicated Perceptions of Gender and Anti-Queer Bullying," showed that many of these teachers taught in a heteronormative style, making little mention of sexual minorities (Preston, 2016). These teachers admitted to ignoring the harassment and bullying of queer students and $80 \%$ of teachers blamed the victims (Preston, 2016). The teachers also mentioned they had minimal training, and if provided curriculum, they would gladly take it (Preston, 2016). This shows the invisibility of queer identities as many of the teachers stated that they believed there were few or no queer students at their school (Preston, 2016). This leads to the idea of teachers meaning well but doing harm because of their ignorance. If teachers were better taught then they could better teach students.

The disparity between the sexual majority and the sexual minority lies within the politics of discrimination. Policies often do not protect the LGBTQ community from discrimination which, passively allows discrimination and results in inequality toward the sexual minority. Discrimination is allowed due to the absence of inclusive policies. For example, for decades, all military spouses were invited to attend a spouse club at Fort Bragg, NC. When a female spouse of a female soldier attended the monthly gathering in December 2012, controversy ensued when there was a realization that there was no official policy allowing or disallowing her attendance (Hlad, 2012). This is an example of the vast policy vacuum that allows discrimination against the LGBTQ community across America.

Role-modeling factors into the formation and shaping of stereotypes according to a 2012 study that found medical school professors often had discriminatory practices towards multiple groups including the LGBTQ community (Phillips \& Clark, 2012). Students felt expected to adopt similar beliefs and mannerisms, which demonstrates the tendency to follow role-models' beliefs (Phillips \& Clark, 2012). Instructors teaching medical college students were found to show explicit disdain toward patients with obesity and mental illness, as well as female doctors, immigrants, and homosexuals (Phillips \& Clark, 2012). This could lead to the students taking up 33 negative views of homosexuality and in their practice as doctors treat homosexual patients with less care which can increase the health disparity between homosexuals and heterosexuals (Williams \& Mann, 2017; Phillips \& Clark, 2012). 
The developing brains of high school and collegiate students are vulnerable to the professional position of power that teachers hold. A student confessed,

The references to mental illness always bother me but I don't react. My reasons for these feelings are very personal and as much as I would love to be an advocate I have to wait until I am more established. (Phillips \& Clarke, 2012)

The qualitative results confirm that students are at the mercy of the hidden curriculum used by teachers in institutions of education everywhere (Phillips \& Clarke, 2012). Adults interacting with the students often present their own opinions, intentionally or unintentionally (Gregory \& Fergus, 2017). Research shows that educators' own social and emotional position strongly influences the climate in the school (Gregory \& Fergus, 2017).

A factor that contributes to the formation of stereotypes that negatively affect the LGBTQ community is the traditional binary concept of gender, which assumes two rigid categories of gender (Greenburg \& Gaia, 2019). Research shows that individuals who do not rigidly conform to the binary concept for gender and gender expression are often negatively judged (Greenburg \& Gaia, 2019). Nearly $20 \%$ of students in a study titled, "Interpersonal Contact, Stereotype Acceptance, Gender Role Beliefs, Causal Attribution, and Religiosity as Predictors of Attitudes Toward Transgender Individuals" indicated that they had left K-12 education due to harassment and mistreatment (Greenburg \& Gaia, 2019). Research reflecting evidence of mistreatment of LGBTQ students as young as Kindergarten is alarming.

Gender stereotyping is when there are beliefs about how males and females typically behave combined with beliefs about how they should behave (Koenig, 2018). An example of descriptive stereotyping is assuming that males behave independently would describe how one believes that males typically act (Koenig, 2018). Presuming that a male should look masculine and avoid appearing feminine is prescriptive stereotyping (Koenig, 2018). Female stereotyping includes expecting a female to be nurturing and avoid dominance nor being portrayed as dominant (Koenig, 2018). Male stereotyping may include expecting leadership qualities like decision-making, lack of emotion, or reduced emotional expression.

Causal attribution is the cause that people believe is the basis for the behavior of others (Greenburg \& Gaia, 2019). Stereotypes are built on the causal attribution that people believe about LGBTQ individuals.

Key in the formation and perpetuation of sexuality and gender stereotypes are the teachers in schools who are responsible for presenting sex education to students:

Sexuality education teachers take on the responsibility of providing information, education, and resources to young people about healthy sexuality and sex. Their job often involves negotiating between regulations set forth by school districts, states, and society that define what can and should be taught to young people. (Preston, 2016)

Many teachers who become qualified as a sex education instructor at their respective school find their role rewarding and take pride in addressing concerns of life with the students. The following statement likely represents many teachers of sex education: I feel like you just have such a different role in the school than anybody else, I think it's a great role. I think that I can go home at night knowing that maybe I didn't get them to pass their math regent of whatever, but maybe I touched one kid's life to save their life or stopped something from happening. (Preston, 2016)

However, in “'They're Just Not Mature Right Now': Teachers' Complicated Perceptions of Gender and AntiQueer Bullying," $70 \%$ of high school teachers downplayed the experiences of the LGBTQ students about the bullying of this community (Preston, 2016). One teacher claimed that students were not fully aware of the meaning of the words used in slurs (Preston, 2016). Another teacher reasoned that if no LGBTQ students were present at the time of the bullying remarks, then no harm is done (Preston, 2016). It is important to note these beliefs because the same study found that these teachers were also likely to believe that there were no LGBTQ students at their school (Preston, 2016). Therefore, teachers were less likely to stop bullying against an LGBTQ student, believing that the student was not LGBTQ and the insults did not hurt them, or that none of the students understood what was going on (Preston, 2016). Each participating teacher in this study expressed that they were each individually willing to become more informed educators, but felt a lack of guidance and institutional support (Preston, 2016).

An analysis of the respective sex education materials and policies in all 50 states in the United States revealed that there was a lack of evidence-based content compared to the evidence-based statistics and research currently available that could have been included in the course materials (Hall et al, 2019). This is because $74 \%$ of states relied 
heavily on abstinence-only sexual education, which has proven ineffective. After all, many teens who were taught this method of pregnancy prevention ignore what they were taught (Hall et al, 2019). Also, sexual diversity was missing or discouraged in course materials (Hall et al, 2019). Eight states explicitly stigmatized homosexuality, while only $42 \%$ of the states addressed healthy relationships, sexual decision-making, and sexual violence (Hall et al, 2019). These statistics are important because LGBTQ students are less likely to be informed about safe sex which leads to more unwanted pregnancies and sexual violence in the LGBTQ community. Adolescents who identify as gay, lesbian, or bisexual are statistically more likely to become pregnant, be involved with a pregnancy, and contract a sexually transmitted infection (Hall et al, 2019). Due to the lack of unbiased education to adolescents, combined with the negative stereotyping of the LGBTQ students, the LGBTQ adolescent community may not receive the same level of appropriate education content as the heterosexuals.

Sexual orientation and gender roles are deeply integrated into social expectations and interpretations of interpersonal communication. In high schools where peers regulate gender roles and sexual orientation, the social climate can be harsh and dangerous for the sexual minority. "Peer regulation often leads to victimization, bullying, and harassment of children and youth whom their peers perceive as non-normative, particularly LGBTQ-identified students" (Preston, 2016).

In her article titled "Can Education Reduce Prejudice against LGBT People?" Rebecca Demante contends: Ensuring that these instances of anti-LGBT violence and discrimination do not continue to repeat themselves may require society to turn to one of its oldest tools: education. Reports from GLAAD have found that increased knowledge about LGBT people leads to lower levels of discomfort toward this community, and thus can reduce anti-LGBT discrimination. (Demante, 2016)

The instances to which Demante was referring were such facts as that LGBTQ people are twice as likely to have a mental health disorder, yet the Tennessee House of Representatives passed a bill that denies mental health services to LGBTQ people (Demante, 2016).

According to the State Equality Index (SEI), laws in North Carolina show that LGBTQ youth are legally permitted to participate in sports, are protected from cyberbullying, and have inclusive juvenile justice policies (Human Rights Campaign \& Equality Federation Institute, 2019). Adversely, LGBTQ youth are not considered candidates for alternative discipline in schools, are not required to be included in anti-suicide promotions, are not protected from conversion therapy, and are not included in the sex education curriculum (Human Rights Campaign \& Equality Federation Institute, 2019).

\section{Gap}

The gap in research that I targeted is the prevalence of stereotypes occurring in the population at a high school in North Carolina as opposed to in the general public. Additionally, my research focuses on the effect of education on the population at this high school specifically. Present research conducted in national and foreign populations reflects that education does affect positive change by reducing negative stereotyping against the LGBTQ community. A 2014 study in Canadian high schools is the most similar study geographically and demographically to what I did (Lapointe, 2014). However, no research has yet been conducted within the state of North Carolina.

\section{Methodology}

There were two main surveys shared during this research project. A survey was distributed via email to all teachers and staff at the school, which is approximately 70 people. This survey utilized a mixed-method approach by collecting qualitative and quantitative information through multiple-choice and open-ended responses. This mixed-method approach allows for a general view of the teacher's beliefs and amount of discrimination and allows the teachers to give individualistic input. A second survey is the student survey which was distributed via email to the whole student body 
of about 1200 students. The student survey only collected quantitative information to support participation by the students. Both surveys include multiple-choice questions, and spectrum agree/disagree questions.

The responses from the student survey established the control group for this study. The experimental/test group was a single classroom of students including the attending teacher. The test group was presented with education about stereotypes and the LGBTQ community in the form of a digital presentation facilitated, narrated by the researcher. The educational presentation included peer-reviewed content explaining the definition and examples of stereotyping in general, followed by statistics and examples of stereotyping by the general population specifically toward the LGBTQ community. Before the presentation, the students were asked to fill out a pre-education survey. After the presentation, the same students were asked to fill out an identical post-education survey. The post-education survey was compared to the pre-education survey to measure changes in stereotypical beliefs post-education about stereotypes.

\section{Results and Findings}

The teacher survey included seventeen questions about demographics as well as their stereotyping and their perception of student stereotyping. The majority of teachers who responded were female (63.2\%) (figure 4.b.2) and had at least 15 years of teaching experience (63.2\%) (figure 4.b.1). Of the respondents, $89.5 \%$ personally knew a member of the LGBTQ community (figure 4.b.4). This is important because the intergroup contact theory which contends greater contact increases acceptance (Greenberg \& Gaia, 2019).
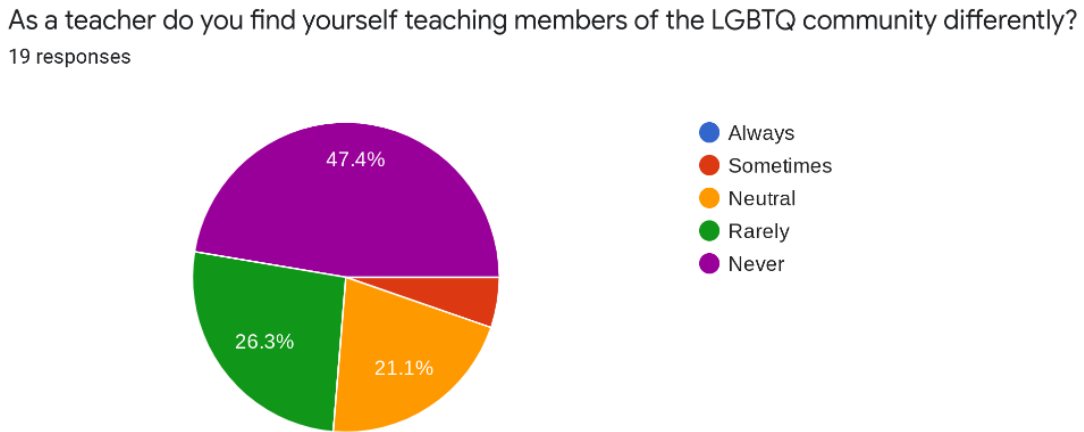

\section{4.b.5}

As figure 4.b.5 indicates, most respondents either rarely or never teach members of the LGBTQ community differently. This result is important because it presents that sexual orientation and gender identity have little to no effect on the quality of education that is received by the sexual minority.

Teachers overwhelmingly agree that being in the presence of LGBTQ students does not make them feel uncomfortable (figure 4.b.7). This result is important because it supports the fact that $73.7 \%$ of teachers never or rarely teach students differently. After all, if the teachers feel uncomfortable, they are more likely to treat that student differently. The results in figures 4.b.3, 4.b.9, 4.b.15 all support each other regarding homophobic slurs and discrimination in the classroom. It was found that $88.8 \%$ of teachers either completely or mostly agree that they would recognize discrimination in their classroom (figure 4.b.9). When the teachers were asked if they have stepped in upon hearing a homophobic slur, $94.8 \%$ said sometimes or always with $31.2 \%$ saying always and $63.2 \%$ saying sometimes (figure 4.b.3). An open-ended response question asked if a teacher hadn't spoken up why they didn't (figure 4.b.15). It was found that $25 \%$ said that they sometimes didn't speak up and that they did so to avoid confrontation and to not interrupt their class. This also showed that the teachers seemed to be more perceptive of homophobic comments and bullying 
than in my literature sources with $88.8 \%$ relatively sure that they could spot a homophobic comment and $94.8 \%$ saying that they would speak up if they heard discrimination (figures 4.b.3 and 4.b.9). This is the opposite of one study in my literature review that found that $70 \%$ of high school teachers downplayed the experiences of the LGBTQ students about the bullying of this community (Preston, 2016). $73.3 \%$ of respondents believe that homosexuality is natural while $13.3 \%$ believe it is deviant and $13.3 \%$ believe it is a mental illness (figure $4 . b .10$ ). Similarly, $83.3 \%$ of teachers believed homosexuality should be legal, accepted, or tolerated, with only $16.7 \%$ believing homosexual behavior should be monitored (4.b.14). An overwhelming majority of teachers did not fall for the cliche that lesbians play softball (figure 4.b.11).

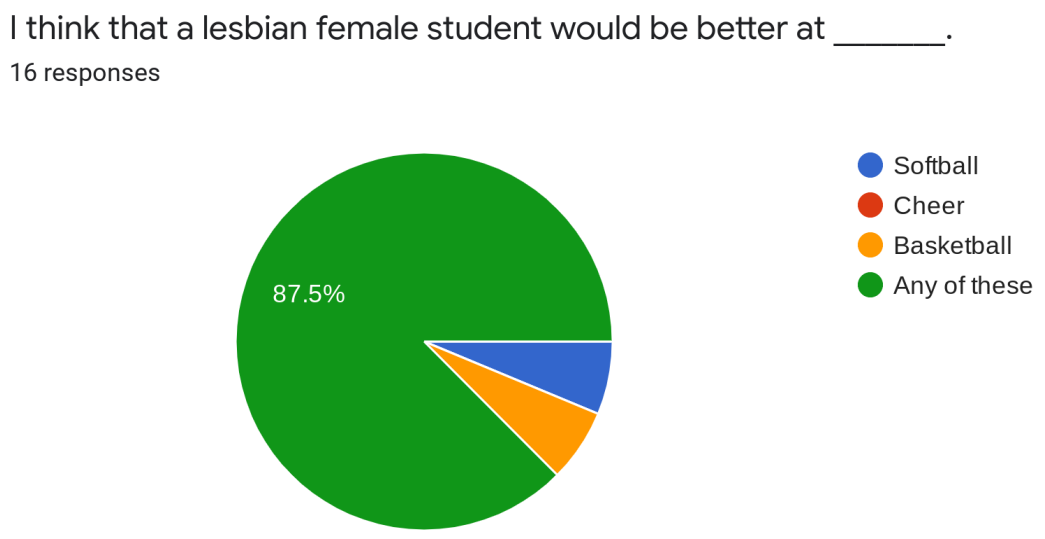

\section{4.b.11}

The majority (64\%) of teachers believed that stereotyping against the LGBTQ community was common (figure 4.b.16). While $27 \%$ believed it was uncommon and $9 \%$ were unsure (figure 4.b.16). The teachers that believed it was common reported the main stereotypes and discrimination being slurs and the belief that gay boys are feminine and lesbian girls are masculine. This shows that teachers know about the stereotypes that the students hold against the LGBTQ community within the student body. Figures 4.b.6 and 4.b.17 support each other. Of the teachers surveyed, $42.2 \%$ agree that they are adequately trained to meet the needs of students and $42.1 \%$ were neutral or unsure (figure 4.b.6). The teachers were asked if professional development should be provided to meet the needs of LGBTQ students and $36 \%$ of the teachers said no (figure 4.b.17).

It was found that only $21 \%$ of teachers are interested in more information on how to meet the needs of LGBTQ students (figure 4.b.17). This is the opposite of what was found in “'They're Just Not Mature Right Now': Teachers' Complicated Perceptions of Gender and Anti-Queer Bullying," which found that most teachers were interested in more information on how to meet the needs of LGBTQ students (Preston, 2016).

The student survey included 14 questions in three main groups: demographics, amount of discrimination at school, and personal opinions about the LGBTQ community. Of the students that responded $58.3 \%$ were female; however, two people did declare their gender identity as an attack helicopter (figure 5.b.1). 41 of the 72 student respondents were underclassmen with $38.9 \%$ being sophomores and $18.1 \%$ being freshmen while there were $31.9 \%$ juniors and only $11.1 \%$ were seniors (figure 5.b.2). This is important as overtime, adolescents' attitudes tend to become more favorable toward the LGBTQ community (Smith et al, 2015). The majority of students (83.3\%) reported seeing either open acceptance or toleration of gay students while only $16.7 \%$ of students reported seeing discrimination (figure 5.b.3) While $54.2 \%$ of students believed that they could correctly spot discrimination (figure 5.b.9). This is important because it shows that discrimination is not a major problem while noting it occasionally occurs. $84.7 \%$ of students believe that stereotyping based on sexual orientation is normal in American high schools (5.b.14). 


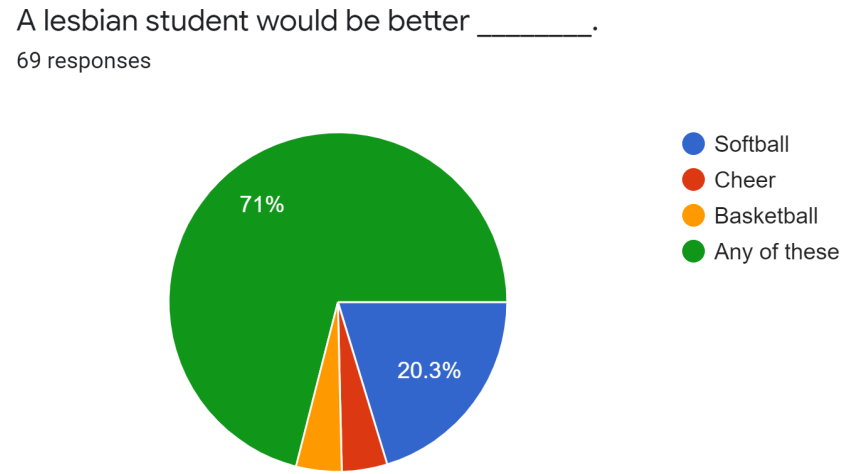

\section{$5 . b .13$}

One in five students believes the cliche that lesbians play softball. This shows that many students find it easier to follow common stereotypes in some cases.

$77.1 \%$ of students personally know someone that is part of the LGBTQ community (5.b.5). This might correlate with the lower levels of discrimination because of the intergroup contact theory which is when the more contact two groups have with each other the more accepting they become of each other. So if a large part of the population has personal contact with someone from the LGBTQ community they are less likely to be discriminatory, which is true in this population as $73.6 \%$ believe that homosexuality is natural (5.b.10). Also, $84.7 \%$ of this population would completely accept a friend who came out as gay (5.b.11) The fact that $94.3 \%$ accept or befriend gay people makes sense in this context (5.b.7). However, $20.8 \%$ of students reported feeling very uncomfortable in the presence of gay people (5.b.6).

The pre-education and post-education surveys were identical and included 19 questions in four main groups: demographics, amount of discrimination at school, personal opinions about the LGBTQ community, and questions to test knowledge about the LGBTQ community. All of the participants were female, something similar happened in "Interpersonal Contact, Stereotype Acceptance, Gender Role Beliefs, Causal Attribution, and Religiosity as Predictors of Attitudes Toward Transgender Individuals" where most of the respondents were female (Greenburg \& Gaia, 2019) (figures 6.b.1 and 7.b.1). In that study, the researchers found that the females were more accepting of transgendered people than males; therefore, this sample only shows the views of females which is likely different than the views of males (Greenburg \& Gaia, 2019) (figures 6.b.1 and 7.b.1). Six participants took the pre-education survey and five took the post-education survey; many of the questions in the pre-education and post-education surveys were the same as the questions in the student survey and the answers were very similar between the three surveys. However, some answers were notably different such as all the participants in the educational presentation knew someone who was a member of the LGBTQ community (figures 6.b.5 and 7.b.5). Also, the group who participated were originally more accepting of the LGBTQ community compared to the general population, this is important because it shows that the group that was educated was more accepting which follows a study mentioned in the lit review that education has a positive effect on the increase of toleration (Smith et al, 2015) (figures 5.b.7 and 5.b.7).

They were more likely to accept a friend who was homosexual (100\% vs $84.7 \%)$, more likely to believe that homosexuality is natural ( $100 \%$ vs $73.6 \%$ ), and less likely to tease someone for being gay ( $0 \%$ vs $5.7 \%$ ) (figures 5.b.7, 5.b.10, 5.b.11, 7.b.7, 7.b.10, and 7.b.11).

As seen in figures 6.b.13 and 7.b.13 the education seemed to have a low-grade negative impact on stereotypes as stereotyping increases from $0 \%$ to $20 \%$ after the educational presentation, which is the opposite contention of a literature source (Smith et al, 2015). Figure 6.b.13 shows the level of stereotyping before the educational presentation and 7.b.13 shows the level after the presentation. This increase in stereotyping is the possible negative result of the educational presentation. This literature source states that the combination of time plus education renders an increase in tolerance toward disadvantaged groups, thus accelerating the rate at which tolerance increases and manifests itself 
in social settings (Smith et al, 2015). The low level of participation may be affecting this since the difference is by one response but it changes the percent statistics by $20 \%$.

The participants did learn from the education portion. This is seen in figures $6 . b .20$ and 7.b.20, before the presentation where the average score was 2.17 out of 5 . After the presentation, the average score increased to 3.2 out of 5 (figures 6.b.20 and 7.b.20). This shows that the participants learned something during the presentation.
Average
$2.17 / 5$ points
Median
$1 / 5$ points
Range
0 - 5 points

Total points distribution
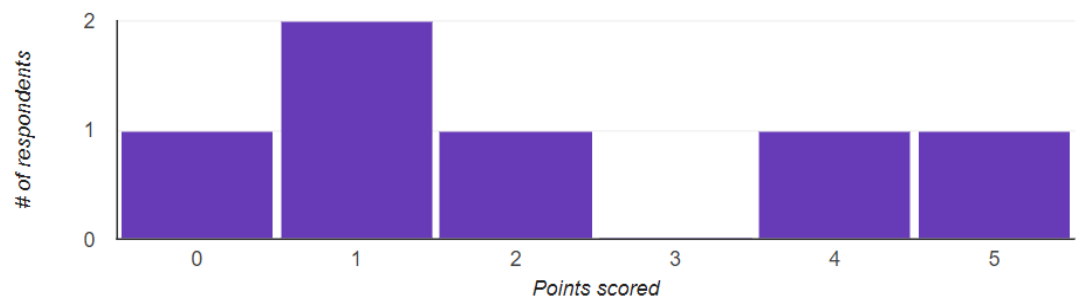

6.b.20

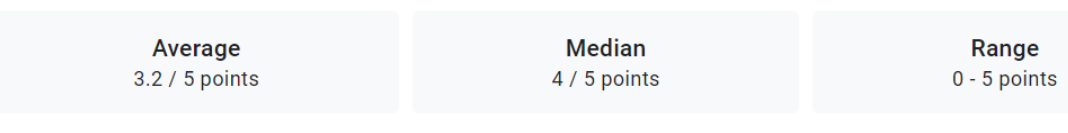

Total points distribution

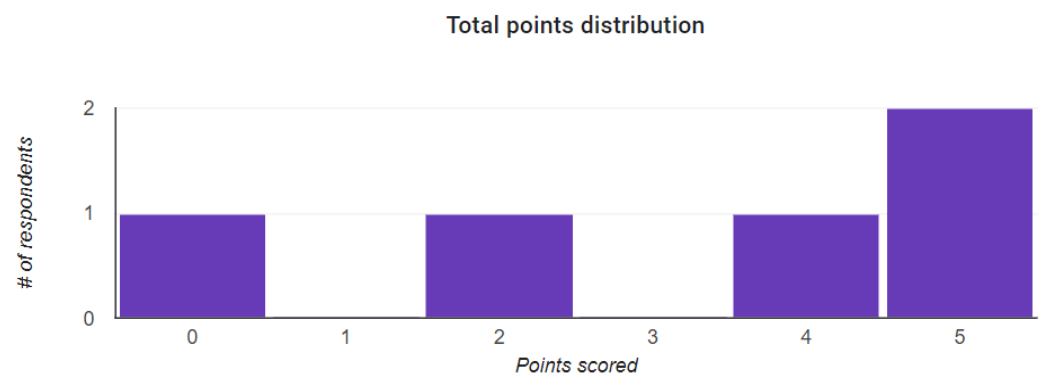

\section{7.b.20}

There is a noticeable trend of generational differences in beliefs about the LGBTQ community. Teachers are more likely to call homosexuality a mental illness compared to students ( $13.3 \%$ of teachers vs. $11.1 \%$ of students) (figures 4.b.10 and 5.b.10). Another generational difference is that students are more likely to believe the cliche of lesbians being better at softball when compared to cheer, basketball, or any sport (20.3\% of students vs. $6.3 \%$ of teachers) (figures 4.b.11 and 5.b.13). Teachers are more comfortable than the student body is around its peer student LGBTQ community (figures 4.b.7 and 5.b.6). 
I feel (or I have felt) uncomfortable in the presence of students whom I know or believe to be in the LGBTQ community because of their sexual orientation.

19 responses

4.b.7

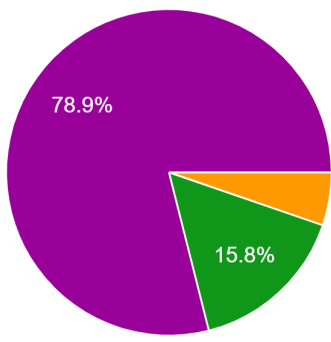

In the presence of peers whom I know or believe to be gay, I feel:

72 responses

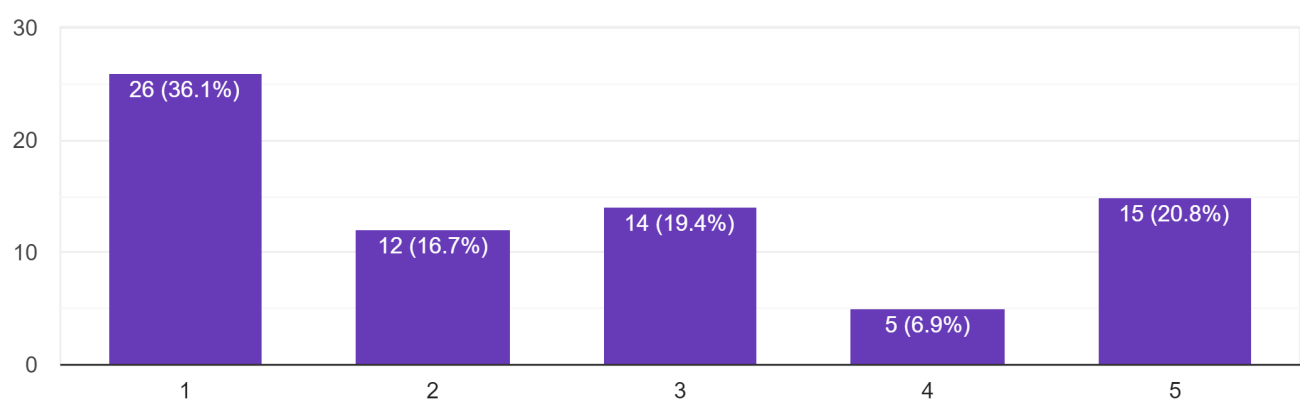

\section{$5 . \mathbf{b . 6}$}

very comfortable-very uncomfortable

The majority (64\%) of teachers believed that stereotyping against the LGBTQ community was common (figure 4.b.16), while 27\% believed it was uncommon and $9 \%$ were unsure (figure 4.b.16). The teachers that believed it was common reported the main stereotypes and discrimination being slurs and the belief that gay boys are feminine and lesbian girls are masculine. However, the student body viewed the level of stereotyping differently with the majority of students $(83.3 \%)$ reporting seeing either open acceptance or toleration of gay students while only $16.7 \%$ of students reported seeing discrimination (figure 5.b.3).

\section{Limitations}

The topic of stereotypes is tricky as everyone has their own bias and ideas. Due to LGBTQ topics being controversial and the fact that most people avoid talking about controversial topics reduced the participation in this study. About $6 \%$ of the student body took the survey and of that $6 \%$ not all answered every question. Only $30 \%$ of teachers taking the survey and not every teacher who participated answered every question. The people who answered were more likely than the general population to be accepting because some of those who don't accept the LBGTQ community refused to take the survey. This would lead to a lower level of discrimination shown in the survey responses than is true in the general population of the student body.

Eighteen out of twenty-four students exited the room before the educational presentation. Most students cited religion while exiting the room, "Interpersonal Contact, Stereotype Acceptance, Gender Role Beliefs, Causal 
Attribution, and Religiosity as Predictors of Attitudes Toward Transgender Individuals" found that religion contributes to anti-trans and homophobic beliefs (Greenberg \& Gaia, 2019). Before the education presentation, the students were made aware that participation was voluntary. Six female students remained in the room for the educational presentation. The researcher suspects some compromise in the results from the pre-education and post-education surveys, due to privileged information regarding the sexual orientation and friend groups of the participants in the test group.

The researcher admits to personal bias towards LGBTQ concerns because they are part of the LGBTQ community. Since the researcher was aware of their bias they made sure while writing the paper to use peer-reviewed sources and used a computer to help create the data for the findings.

\section{Future Direction}

This research could be more fully explored by comparing college student populations to high school student populations to see if there is a difference in acceptance levels of the LGBTQ community. A generational difference of beliefs was observed during this study between Generation $\mathrm{Z}$ high school students versus baby boomers and Generation $\mathrm{X}$ teachers. Further studies should explore those generational differences and nuances in stereotyping. Blind study methods are recommended for future research since participation was reduced by overt disclosure of LBGTQ content; this is due to LGBTQ topics being controversial and the fact that most people avoid talking about controversial topics.

\section{Conclusion}

In conclusion, it is very hard to study the existence of and formation of stereotyping because it requires subjective material, difficult to obtain because people are often unwilling to discuss and disclose their raw thoughts and feelings regarding this topic. Most previous research involved open-ended questions and had very few hard numbers, due to the subjective nature of data required to evaluate this topic in a research method. My new understanding is that there are low levels of discrimination and stereotyping in high school studied in this research. It also found that the educational presentation presented had a low-grade negative impact against stereotyping, effectively increasing stereotyping. Data collected in this research was credible to the point that both discrimination and non-discrimination were detected, however, the true extent of each is difficult on which to make a specific contention nor measure given the limitations previously cited in this study.

\section{Acknowledgments}

I would like to acknowledge my AP Research teacher, Mrs. Vajner, who helped me a great deal in being able to conduct this research. She was also rather helpful with the proofreading process and motivating me to complete my work.

\section{References}

Berg, N., \& Lien, D. (2002). Measuring the effect of sexual orientation on income: Evidence of discrimination? Contemporary Economic Policy, 20(4), 394-414. DOI: 10.1093/cep/20.4.394

Boso, L. A. (2017). Dignity, Inequality, and Stereotypes. Washington Law Review, 92(3), 1119-1183. 
Chaudoir, S. R., Wang, K., \& Pachankis, J.E. (2017). What reduces sexual minority stress? A review of the intervention “toolkit.” The Journal of Social Issues, 73(3), 586-617. DOI: 10.1111/josi.12233

Damante, R. (2016, June 16). Can Education Reduce Prejudice against LGBT People? Retrieved from https://tcf.org/content/commentary/can-education-reduce-prejudice-lgbt-people/

Dreshcer, J. (2015). Out of DSM: Depathologizing Homosexuality. Behavioral sciences (Basel, Switzerland), 5(4), 565-575. https://doi.org/10.3390/bs5040565

Evripidou, D., \& Çavuşoğlu, Ç. (2015). English Language Teachers’ Attitudes Towards the Incorporation of Gayand Lesbian-Related Topics in the Classroom: the Case of Greek Cypriot EFL Teachers. Sexuality Research \& Social Policy: Journal of NSRC, 12(1), 70.

Garbers, S., Heck, C.J., Gold, M.A., Santelli, J.S. \& Bersamin, M. (2018). Providing culturally Competent care for LGBTQ youth in school-based health centers: a needs assessment to guide quality of care improvements. The Journal of School Nursing, 34(6), 424. DOI: 10.1177/1059840517727335

Greenburg, Jordan \& Gaia, A. Celeste. (2019). Interpersonal Contact, Stereotype Acceptance, Gender Role Beliefs, Causal Attribution, and Religiosity as Predictors of Attitudes Toward Transgender Individuals. Psi Chi Journal of Psychological Research. 24(1). 18-32. https://doi.org/10.24839/2325-7342.JN24.1.18

Gregory, A. \& Fergus, E. (2017). Social and Emotional Learning and Equity in School Discipline. Future of Children, 27(1), 117-136. DOI: 10.1353/foc.2017.0006

Hall, W. J., Jones, B. L. H., Witkemper, K. D., Collins, T. L., Rodgers, G. K. (2019). State policy on school-based sex education: a content analysis focused on sexual behaviors, relationships, and identities. American Journal of Health Behavior. 43(3): 506-519. DOI: https://doi.org/10.5993/AJHB.43.3.6

Hettinger, Vanessa E., \& Vandello, Joseph A. (2014). Balance without equality: Just world beliefs, the gay affluence myth, and support for gay rights. Springer Science+Business Media. DOI: 10.1007/s11211-014-0226-2

Hlad, J. (2012). Same-sex spouse not allowed to join group at Fort Bragg. Retrieved April 2020, from https:/www.stripes.com/news/same-sex-spouse-not-allowed-to-join-group-at-fort-bragg-1.200491

Human Rights Campaign \& Equality Federation Institute. (2019). 2019 State Equality Index: A Review of State Legislation Affecting the Lesbian, Gay, Bisexual, Transgender and Queer Community and a Look Ahead in 2020.

Retrieved from https://assets2.hrc.org/files/assets/resources/HRC-SEI-2019-

Report.pdf? ga=2.33632865.1377457351.1587312451-339927564.1587312451

Human Rights Campaign. (2019). HRC's 2019 State Equality Index. Retrieved April 2020, from https://www.hrc.org/campaigns/state-equality-index

Iida, P. C., \& McGivern, C. T. (2019). Creating an LGBTQ+-Affirming Locker Room: Education For Prevention. Multicultural Education, (2).

International Travel. (2019, November 6). Retrieved April 2020, from https://ravel.state.gov/content/travel/en/international-travel/before-you-go/travelers-with-special-considerations/lgbti.html 
Koenig, A. M. (2018). Comparing prescriptive and descriptive gender stereotypes about children, adults, and the elderly. Frontiers in Psychology. 9:1086. DOI: 10.3389/fpsyg.2018.01086

Lapointe, Alicia. Gay-straight alliance (GSA) members' engagement with sex education in Canadian high school. Sex Education. No 2014, Vol. 14 Issue 6, p707-717.

Linville, D. (2017). Unexpected Bodies and Pleasures: Sexuality and Gender in Schools. Critical Questions in Education, (4 SI), 377.

McCormick, Marcia L. (2017). Stereotypes as Channels and the Social Model of Discrimination. Saint Louis University Public Law Review, Vol. 36. No. 2017-10.

Meyer, E. J., Taylor, C., \& Peter, T. (2015). Perspectives on gender and sexual diversity (GSD)-inclusive education: comparisons between gay/lesbian/bisexual and straight educators. Sex Education, 15(3), 221-234. Doi: http://dx.doi.org/10.1080.14681811.2014.979341 